\title{
Framework and Items for Measuring End-User Computing Competency with a Case Study
}

\author{
Chui Young Yoon
}

\begin{abstract}
The end-user computing capability is necessitated for efficiently performing his or her given tasks and improving his or her business performance in an computing environment. A measurement framework and items of an end-user computing competency is extracted from the major components of a general computing competency. Through a survey measurement of 287 respondents, this study performed factor and reliability analyses, and proposed a 15-item framework that can examine an end-user computing competency in an organizational computing environment. The application of the measure is confirmed by applying it to measuring the computing competency of the end-users in a firm computing environment and by presenting the measurement results for them.
\end{abstract}

Index Terms-End-User computing, competency, framework, measurement items.

\section{INTRODUCTION}

In a computer system environment, the end-users use their computing systems for performing the end-users' given tasks. In this environment, we can think that their computing ability have an effect on the performance of their tasks in a computing environment. Hence, this research considers the measures to efficiently examine the end-user computing ability and improve it for raising his or her business completion and the competitiveness of an enterprise. But the researches on the measurement of the end-user computing ability have not actively executed, and these studies focus on specific software skills, professional skills, and operational skills and so on [1]-[3]. For the end-users effectively accomplish their tasks in a computing environment, they have to be qualified with not fragmentary computing skills but the total computing ability including the concepts, knowledge, application, and experience departments. The measurement scale suitable for examining end-user computing ability in a whole computing capability perspective are very important to effectively manage and improve the computing capability that an end-user can efficiently execute the given tasks in a computing environment. That is, the computing capability of an end-user is a critical factor to raise his or her business execution and results, and it also connects with a firm management performance.

Therefore, this study presents a measurement framework

Manuscript received August 26, 2013; revised October 20, 2013. The research was supported by a grant from the Academic Research Program of Korea National University of Transportation in 2013.

Chui Young Yoon is with the Department of IT Applied-Convergence, Korea National University of Transportation, Chungbuk, 368-701, South Korea (e-mail: yoon0109@ut.ac.kr). and items scale for gauging a perceived end-user computing competency to efficiently perform his or her business tasks in a firm of computing environment.

\section{END-USER COMPUTING COMPETENCY}

\section{A. Concepts of End-User Computing}

In previous literature, most of studies define that the end-user is an individual who directly interacting with his or her computer [4]-[6]. End-user computing refers to direct interaction with application software by managerial, professional, and operating level personnel in user departments [7], [8]. So, the end-user computing defines that an end-user directly interacts with computer application software and computing system in his or her departments. This study uses these definitions of the end-user computing and it includes the creative application of computing knowledge, solutions and applications, and computing systems to his or her tasks in order to improve his or her business performance.

\section{B. End-User Computing Competency Construct}

Generally speaking, competency is the total set of knowledge, skills, and attitudes as the action characteristics of an organizational member that can do his or her tasks outstandingly in an organizational environment [9]. The competency is a set of observable performance dimensions, including individual knowledge, skills, attitudes, and behaviors, as well as collective team, process, and organization capabilities that is linked to high performance, and provides the organization with sustainable competitive advantage [10]. And, the competency is a measurable pattern of knowledge, skill, abilities, behaviors, and other characteristics that an individual needs to perform work roles or occupational functions successfully [11]. Competency is defined as one's characteristics that can differentiate significantly between effective and ineffective performance [12]. Competency is suggested as more precise definition that describes competency as work-related personal attributes; knowledge, skills, and values that individuals draw upon to do their work well [13]. Brownell [14] defines competency as a skill or personal attribute/ability that is required to be effective on the job that is critical to achieving targeted outcomes. The competency is a set of knowledge, skills, abilities, or other characteristics that differentiates high from average performance [15]. Competency is a total set of knowledge, skills, and attitudes which function as the action characteristics of an organizational member who can do his task outstandingly in an organizational environment [16]. Spencer \& Spencer [16] presented five major components of 
competency: Motives, Traits, Self-concepts, Knowledge, and Cognitive and Behavioral Skills. In general competency, individual characteristics such as motives, traits, self-concepts and knowledge lead to skills, and the action of a person with skills has an effect on the performance of his or her business from a computing perspective. In other words, computing competency is to transform general competency into a type of competency based on a computing perspective.

Hence, the end-user computing competency (ECC) can be defined as the total set of knowledge, technology, skills and attitudes which function as action characteristics of an organizational member who can do his or her task outstandingly in a computing environment. In other words, ECC indicates individual total ability to apply computing technology, solutions, and computing systems to his or her tasks in a computing environment.

This study generated 29 items to measure an end-user computing competency based on the definition and components of computing competency in previous research.

\section{METHOD}

The construct validity of the measurement items was studied by many researchers. Kerlinger (1978) presented two methods of construct validation: 1) correlations between total scores and item scores, and 2) factor analysis [17]. Doll \& Torkzadeh (1988) [18] and Etezadi-Amoli \& Farhoodmand (1996) [19] used factor analysis to verify the validity of the measurement tool construct. Torkzadeh \& Doll (1999) [20] and Torkzadeh \& Lee (2003) [1] used correlation analysis to verify the validity of the measurement tool construct. This study is likely to verify the validity of the measurement instrument construct and the extraction of adequate items by a factor analysis and reliability analysis. The ratio of sample size to number of measurement items (11:1) was above the minimum (10:1) ratio suggested for factor analysis by Kerlinger. The measurement questionnaire used a five-point Likert-type scale; where, 1: not at all; 2: a little; 3: moderate; 4: good; 5: very good. The survey was gathered data from a variety of industries, and business departments and positions.

\section{A. Sample Characteristics}

A sample of 287 usable responses was obtained from a variety of industries, business departments and positions, and from management levels with considerable experience. All respondents had college or university degrees in: humanities and society (13.2\%), management and economics (23.7\%), engineering $(48.8 \%)$, and science $(14.3 \%)$. The industries represented in the sample were manufacturing $(10.7 \%)$, construction $(9.4 \%)$, finance, banking and insurance (18.7\%), transportation, communication and services (29.7\%), and information consulting and system implementation services (31.5\%). The respondents identified themselves as top managers $(4.3 \%)$, middle managers $(45.3 \%)$, or workers $(50.4 \%)$. The respondent had on average of 8.6 years of experience (S.D. $=1.061)$ in their field, their average age was 34.9 years old (S.D.=5.712). The survey method used in this measurement questionnaire was based on two kinds of collection methods: by direct collection and e-mail.

\section{B. Factor and Reliability Analysis}

The collected questionnaires were analyzed by using SPSS ver.12.0 software. Items were excluded when their correlation with the collected item-total was $<0.5$ or when their correlation with the criterion scales was $<0.6$ [11]. The correlations with the corrected item-total and the criterion item were significant at $p<0.01$ and similar to those used by others in previous researches. The elimination was considered high enough to ensure that the retained items were adequate measures of the end-user computing competency.

TABLE I: FACTOR LOADINGS, CORRECTED ITEM-TOTAL CORRELATION AND COEFFICIENTS ALPHA OF THE EXTRACTED ITEMS

\begin{tabular}{|c|c|c|c|c|c|c|}
\hline \multirow{2}{*}{ Variable } & \multicolumn{4}{|c|}{ Factor Loading } & \multirow{2}{*}{$\begin{array}{c}\text { Corrected } \\
\text { Item-Total } \\
\text { Correlation }\end{array}$} & \multirow{2}{*}{$\begin{array}{c}\text { Coefficients } \\
\text { Alpha }\end{array}$} \\
\hline & Factor 1 & Factor 2 & Factor 3 & Factor 4 & & \\
\hline V01 & 0.716 & & & & 0.495 & \multirow{3}{*}{0.813} \\
\hline V03 & 0.751 & & & & 0.561 & \\
\hline V06 & 0.807 & & & & 0.653 & \\
\hline V09 & & 0.733 & & & 0.713 & \multirow{4}{*}{0.825} \\
\hline V11 & & 0.678 & & & 0.618 & \\
\hline V12 & & 0.811 & & & 0.578 & \\
\hline V17 & & 0.734 & & & 0.741 & \\
\hline V19 & & & 0.778 & & 0.705 & \multirow{5}{*}{0.901} \\
\hline V20 & & & 0.813 & & 0.721 & \\
\hline V22 & & & 0.674 & & 0.589 & \\
\hline V23 & & & 0.835 & & 0.727 & \\
\hline V24 & & & 0.725 & & 0.587 & \\
\hline V26 & & & & 0.787 & 0.669 & \multirow{3}{*}{0.803} \\
\hline V27 & & & & 0.812 & 0.727 & \\
\hline V29 & & & & 0.733 & 0.713 & \\
\hline
\end{tabular}

* Significant at $P \leq 0.01$

The developed measurement items were verified through factor analysis and reliability analysis, and it was used to identify the underlying factors or components that comprise the ECC construct. So, the inadequate measurement items for the developed scale were deleted by the analysis results. These deletions resulted in a 15-item scale for measuring an ECC. Each of the 15 items had a factor loading $>0.674$ and the coefficients alpha of 4 potential factors had the values $>$ 0.803. The descriptions and loadings for the 15 items are presented in Table I, and grouped by their high factor loading. Each of the 15 items had a corrected item-total correlation > 0.561 . The correlation for each of the 15 items was positive and significant ( $p=0.01$ or below). This 15 -item measure had the reliability (Cronbach's alpha) of 0.90 and a criterion-related validity of 0.80 . Hence, the measurement items with a validity and reliability were extracted by carrying a factor analysis as shown in Table I.

\section{Content Validity}

Content validity indicates the representativeness of the item content domain and is the basic conceptual criterion related to construct validity [21]. As Churchill [22] reported that "specifying the domain of the construct, generating items that exhaust the domain, and subsequently purifying the resulting scale should produce a measure which is content or face valid and reliable", it means that the instrument has to consider all aspects of the construct being measured. The rigorous procedures used to conceptualize and operationalize the ECC construct, the interviews with computing 
practitioners and experts in our research center, and the purification procedures, suggest that the refined ECC instrument retains good content validity [23].

\section{Construct Validity}

Construct validity is used to examine how well the results obtained from using the measure fit with the theories that lie behind the design of the instrument. There are two common forms of construct validity, convergent and discriminant validity [21], [24]. This research uses two methods to confirm the construct validity of ECC: (1) the correlation matrix approach to investigate construct validity of the developed ECC measure [25]; (2) correlation coefficients between each dimension of ECC scale and average score of the ECC scale. In the correlation matrix methods, this research examines convergent validity by determining whether relationships between scales of the same factor are higher than zero and large enough to execute discriminant validity analysis [23], [26]. We also examine discriminant validity by counting the number of times that an item had a higher correlation with items of other factors than with those of its own factor [25]. The correlation matrix shows only five violations for 398 potential comparisons.

TABLE II: CORRELATION MATRIX OF ECC MEASURES

\begin{tabular}{|c|c|c|c|c|c|c|c|c|c|c|c|c|c|c|}
\hline$\overline{\mathrm{V03}}$ & 0.47 & & & & & & & & & & & & & \\
\hline V06 & 0.53 & 0.58 & & & & & & & & & & & & \\
\hline V09 & 0.36 & 0.27 & 0.42 & & & & & & & & & & & \\
\hline V11 & 0.37 & 0.35 & 0.29 & 0.48 & & & & & & & & & & \\
\hline V12 & 0.25 & 0.36 & 0.39 & 0.55 & 0.54 & & & & & & & & & \\
\hline V17 & 0.31 & 0.45 & 0.29 & 0.59 & 0.62 & 0.58 & & & & & & & & \\
\hline V19 & 0.41 & 0.34 & 0.39 & 0.33 & 0.29 & 0.32 & 0.38 & & & & & & & \\
\hline V20 & 0.44 & 0.33 & 0.28 & 0.44 & 0.27 & 0.38 & 0.29 & $9 \mathbf{0 . 5 6}$ & & & & & & \\
\hline V22 & 0.38 & 0.35 & 0.38 & 0.36 & 0.39 & 0.36 & 0.34 & $4 \quad 0.58$ & 0.61 & & & & & \\
\hline V23 & 0.29 & 0.38 & 0.25 & 0.31 & 0.44 & 0.33 & 0.35 & $\begin{array}{ll}5 & 0.49\end{array}$ & 0.53 & $\begin{array}{ll}3 & 0.59\end{array}$ & & & & \\
\hline V24 & 0.41 & 0.27 & 0.33 & 0.37 & 0.28 & 0.38 & 0.24 & $4 \quad 0.56$ & 0.61 & 10.54 & 0.58 & & & \\
\hline V26 & 0.38 & 0.31 & 0.36 & 0.31 & 0.35 & 0.36 & 0.25 & $\begin{array}{ll}5 & 0.27\end{array}$ & $7 \quad 0.31$ & 10.30 & 0.32 & 0.39 & & \\
\hline V27 & 0.32 & 0.33 & 0.38 & 0.36 & 0.32 & 0.35 & 0.38 & $\begin{array}{ll}8 & 0.27\end{array}$ & $7 \quad 0.36$ & 50.33 & 0.37 & 0.36 & 0.57 & \\
\hline V29 & 0.38 & 0.35 & 0.36 & 0.38 & 0.29 & 0.31 & 0.38 & $\begin{array}{ll}8 & 0.37\end{array}$ & $7 \quad 0.39$ & 0.42 & 0.38 & 0.37 & 0.51 & 0.55 \\
\hline
\end{tabular}

Additionally, the computation of correlation coefficients between each dimension of the ECC measure and the average score of the ECC scale present that each dimension correlates significantly, and appears to be strongly related to, the average score of the ECC instrument, suggesting good construct validity, as shown in Table III.

TABLE III: CORRELATION COEFFICIENTS BETWEEN EACH FACTOR AND OVERALL ECC MEASURE

\begin{tabular}{|c|c|c|c|c|c|}
\hline \multirow[b]{2}{*}{ Division } & \multicolumn{5}{|c|}{ Factor Correlation Matrix } \\
\hline & $\begin{array}{l}\text { Computing } \\
\text { Concepts }\end{array}$ & $\begin{array}{l}\text { Computing } \\
\text { Knowledge }\end{array}$ & $\begin{array}{l}\text { Computing } \\
\text { Application }\end{array}$ & $\begin{array}{l}\text { Computing } \\
\text { Experience }\end{array}$ & ECC \\
\hline \multicolumn{6}{|l|}{$\begin{array}{l}\text { Computing } \\
\text { Concepts }\end{array}$} \\
\hline $\begin{array}{l}\text { Computing } \\
\text { Knowledge }\end{array}$ & 0.39 & & & & \\
\hline $\begin{array}{l}\text { Computing } \\
\text { Application }\end{array}$ & 0.40 & 0.57 & & & \\
\hline $\begin{array}{l}\text { Computing } \\
\text { Experience }\end{array}$ & 0.37 & 0.41 & 0.46 & & \\
\hline $\mathrm{ECC}$ & 0.42 & 0.53 & 0.61 & 0.47 & \\
\hline
\end{tabular}

\section{MEASUREMENT FRAMEWORK AND ITEMS}

By exploring the factor analysis and reliability analysis on the first measurement items, we extracted 15 items to an ECC and the extracted items were identified as 4 factor groups. The 4 factor groups indicate the potential factors to measure the ECC. With investigating the measurement items of each factor, this study generated the 4 potential factors as follows: factor 1: computing concepts (V1, V3, V6); factor 2: computing knowledge (V9, V11, V12, V17); factor 3: computing application (V19, V20, V22, V23, V24); factor 4: computing experience (V26, V27, V29). The four potential factors are considered as the critical measurement factors in this research. Fig. 1 shows the framework and items to measure the ECC based on the four potential factors and 15 measurement items.

The measurement construct has the four measurement factors to efficiently gauge an ECC in a computing environment and the factors are the computing concepts, the computing knowledge, the computing application, and the computing experience. The measurement construct has the four measurement factors to efficiently gauge an ECC in a computing environment and the factors are the computing concepts, the computing knowledge, the computing application, and the computing experience. This instrument may be used for improving ECC across business departments and position levels, and could even serve as a global measure.

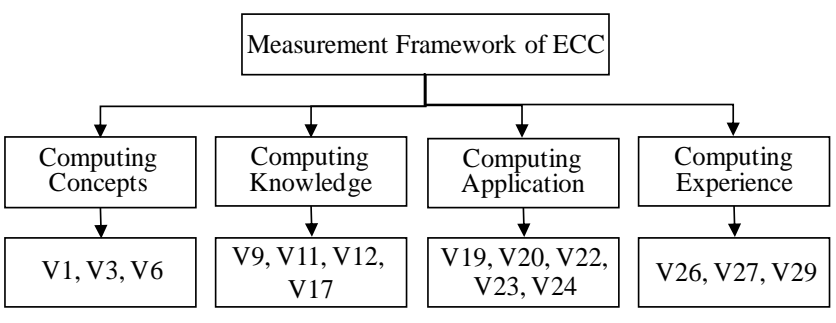

Computing Concepts $(\mathrm{CC})$

V01: Awareness of the Internet and e-Business

V03: Understanding of e-Business progress trends

V06: Ethics and morality in a computing environment

Computing Knowledge (CK)

V09: Knowledge of H/W, S/W, N/W, and D/B

V11: Knowledge of solutions such as ERP, SCM, CRM, and KMS etc.

V12: Knowledge of applications such as B2C, B2B, and B2E

V17: Knowledge of computing security measures

Computing Application (CA)

-V19: Use ability for word processing, presentation, and spreadsheets etc.

V20: Utilization ability for the solutions of ERP, SCM, CRM, and KMS etc

V22: Application ability of solutions and computing systems for B to E, $\mathrm{B}$ to $\mathrm{C}$, and $\mathrm{B}$ to $\mathrm{B}$

V23: Ability sharing and integrating computing data

V24: Ability establishing and managing security measures

Computing Experience (CE)

V26: Possession of certificate related to computing department

V27: Working experience in computing departments

V29: Completion of education and training related to computing

Fig. 1. Measurement framework and items.

\section{A. Measurement Factors and Items}

The computing concepts which have three measurement items are the realm where measures awareness, understanding, ethics and morality, and security measures related to an end-user computing. It includes the 
measurement items that can identify an end-user computing concepts such as awareness of the Internet and computing, understanding of computing progress trends, and ethics and morality in a computing environment.

The computing knowledge which includes four measurement items indicates the knowledge that an end-user has to know to efficiently apply computing technology, solutions and applications, and computing systems to his or her works. It comprises the items that can gauge the computing knowledge such as knowledge of $\mathrm{H} / \mathrm{W}, \mathrm{S} / \mathrm{W}$, $\mathrm{N} / \mathrm{W}$, and D/B, solution knowledge related to ERP, SCM, $\mathrm{CRM}$, and KMS, application knowledge related to e-business (B2E, B2C, and B2B), and knowledge related to computing security measures.

The computing application which implicates five measurement items is the ability that an end-user can effectively apply the computing knowledge, solutions and applications, and computing systems to his or her business tasks. This measures the competency that utilizes the computing knowledge and skills to do an end-user's given tasks. It includes OA ability such as Spreadsheet, Presentation and Word processing, the ability using business solutions such as ERP, SCM, CRM, and KMS, the ability applying the computing systems to an end-user's work such as e-business of the form B to C, B to B, and B to E, and the skills to establishing and managing the security measures.

The computing experience which comprises three measurement items refers to the potential ability of the ECC by computing certificate, working experience and completion of education and training related to computing departments. This is the crucial factor for the development of computing knowledge and ability, and the extension of computing ability in terms of the breadth and depth of an end-user computing. As shown in Fig. 1, the measurement scale is a critical theoretical construct to measure an end-user's total computing ability that can efficiently perform his or her tasks in a computing environment.

\section{Measurement Method}

This research uses the weight values for each measurement factor in order to develop an efficient scale considered the relative importance of each measurement factor for gauging the ECC. The weight values, as shown in Table IV, were extracted from the analysis results of the questionnaire survey for about 30 experts working in computing and IT departments.

TABLE IV: WEIGHT VALUE OF EACH MEASUREMENT FACTOR

\begin{tabular}{cc}
\hline Measurement Factor & Weight Value \\
\hline Computing Concepts & 0.19 \\
Computing Knowledge & 0.26 \\
Computing Application & 0.32 \\
Computing Experience & 0.23 \\
\hline
\end{tabular}

The measurement method first calculates the measurement values of each measurement factor through the analysis of the measurement results that the end-user is examined by the extracted problems based on the measurement items of each factor, and figures out the measurement indices of each factor by multiplying each weight value by each value of each factor. And, the sum of the measurement indices of each factor becomes the total measurement index of the end-user. In other words, the total measurement index of the ECC is the sum of each measurement index extracted by multiplying each weight value by each measurement value of each factor of the measurement scale.

Hence, the measurement index (MI) of each factor can be presented as Equation (1).

$$
\mathrm{MI}_{\mathrm{MF} i}=\mathrm{MV}_{\mathrm{MF} i} \times \mathrm{WV}_{\mathrm{MF} i}
$$

where, MI MFi: Measurement index (MI) of the $i$ th Measurement Factor.

MV MFi: Measurement Value (MV) of the $i$ th Measurement Factor.

WV ${ }_{\text {MFi }}$ : Weight Value (WV) of the $i$ th Measurement Factor

Here, the sum of the weight values of each factor is 1.00 and $i$ $=1,2,3$ and 4 indicate four measurement factors.

Therefore, the total MI can be defined as Equation (2) with Equation (1):

$$
\text { Total MI }=\sum_{i=1}^{4} \mathrm{MI}_{\mathrm{MF} i}
$$

Here, $i=1,2,3$ and 4 mean the four measurement factors. In this way, this instrument presents the measurement results of ECC based on the total measurement index and the indices of each factor.

\section{CASE StUdy AND AnAlysis Results}

\section{A. Sample Characteristics}

This case study applied the developed measurement scale to 148 end-users working at " $A$ " enterprise in South Korea. The business departments of respondents were identified as follows: strategy plan department: $25.7 \%$; development and maintenance department: $26.4 \%$; business application department: $37.2 \%$ and administration support department: $17.6 \%$. The business positions of respondents were classified as follows; top managers: $4.3 \%$; middle managers: $24.6 \%$ and workers: $71.1 \%$. The respondents had on average 7.3 years of experience ( $\mathrm{SD}=0.603)$, and most respondents $(74.4 \%)$ had college or university degrees.

\section{B. Application and Analysis}

The case study analyzes the measurement results obtained from the administration support department and each business department as the organizational level, and from an end-user working in the administration support department as an example, and explains the meanings of the measurement results on various points of view.

\section{Application and Analysis of Organizational Level}

As the analysis of organizational level, we present the measurement results of each business department of the 
overall organization. The total measurement index of the overall organization is 64.02, and the strategy plan department and the business application department are 62.98 and 67.78 as shown in Fig. 2. The computing competency of the overall organization is quite a high level but the measurement result requires the endeavor to improve it. The measurement results of each business department show that the measurement index of the business application department were higher than those of the other departments.

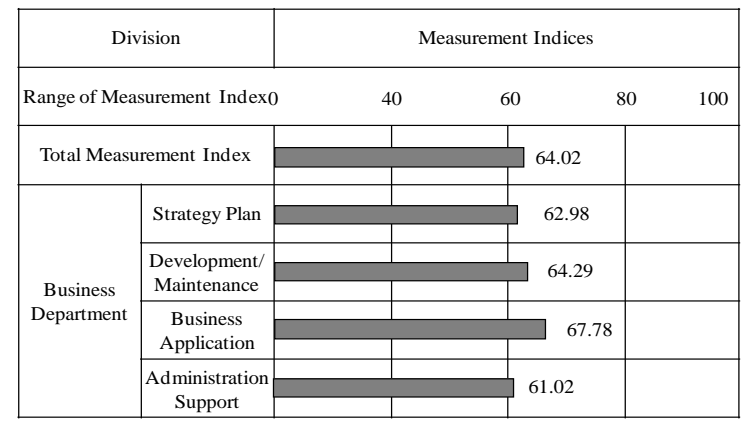

Fig. 2. Measurement indices of each business department.

This is due to the ability to effectively accomplish their tasks by frequently applying computing knowledge, solutions and applications, and computing systems to e-Business of the form B to C (Business to Customer), B to B (Business to Business) and B to E (Business to Employee), and the knowledge and abilities to utilize the various solutions such as ERP (Enterprise Resources Planning), SCM (Supply Chain Management), CRM (Customer Relationship Management), and KMS (Knowledge Management System) in order to do their business tasks in a computing environment. Especially, the end-users in administration support department have to make an effort to raise the general computing competency of their department.

\section{Application and Analysis of a Business Department}

The total measurement index of the administration support department is 64.27 , and it indicates quite a high level. The measurement indices of the strategy plan department are quite a high in the measurement domains of the computing mind, the computing technology and knowledge, and the computing application ability, except for the potential computing ability as shown in Fig. 3. But the measurement index of the computing experience generally is 60.78 and it is the lowest level among the measurement factors.

\begin{tabular}{|c|c|c|c|c|c|}
\hline \multicolumn{2}{|c|}{ Division } & \multicolumn{4}{|c|}{ Measurement Indices } \\
\hline \multicolumn{2}{|c|}{ Range of Measurement Index 0} & 40 & 6 & & 100 \\
\hline \multicolumn{2}{|c|}{ Total Measurement Index } & & \multicolumn{2}{|c|}{64.27} & \\
\hline \multirow{5}{*}{$\begin{array}{l}\text { Measurement } \\
\text { Factor }\end{array}$} & Computing & & \multicolumn{2}{|c|}{63.98} & \\
\hline & Computing & & \multicolumn{2}{|c|}{62.29} & \\
\hline & Computing & & \multicolumn{2}{|c|}{70.02} & \\
\hline & & & \multirow{2}{*}{\multicolumn{2}{|c|}{60.78}} & \\
\hline & Computing & & & & \\
\hline
\end{tabular}

Fig. 3. Measurement indices of each factor of administration support department.
Hence, the end-users of the administration support department should make an effort to improve and develop the computing departments such as the possession of certificate, working experience, and education and training related to computing department in order to effectively improve the organizational computing competency.

\section{E. Application and Analysis of Individual Level}

The measurement results of an end-user working in the business application department (BAD) are taken as an example. The measurement index of each measurement domain is generated by multiplying each weight value by the measurement value of each measurement domain, and the total measurement index is the sum of the measurement indices of each measurement domain. Table $\mathrm{V}$ represents the extraction process of the total measurement index.

TABLE V: EXTRACTION PROCESS OF TOTAL MEASUREMENT INDEX FOR AN END-USER

\begin{tabular}{lccccc}
\hline Division & $\begin{array}{c}\text { Computing } \\
\text { Concepts }\end{array}$ & $\begin{array}{c}\text { Computing } \\
\text { Knowledge }\end{array}$ & $\begin{array}{c}\text { Computing } \\
\text { Application }\end{array}$ & $\begin{array}{c}\text { Computing } \\
\text { Experience }\end{array}$ & Total MI \\
\hline $\begin{array}{l}\text { MI of Each } \\
\begin{array}{l}\text { Factor } \\
\text { Weight Values } \\
\text { of Each Factor }\end{array}\end{array}$ & 62.29 & 61.67 & 65.14 & 60.26 & - \\
$\begin{array}{l}\text { Calculation of } \\
\text { Total MI }\end{array}$ & 11.84 & 16.03 & 20.84 & 13.86 & $\mathbf{6 2 . 5 7}$ \\
\hline
\end{tabular}

The total measurement index of the end-user computing competency is 62.57 as shown in Fig. 4, and it is a little high. Especially, the measurement index of the computing application is very high. This means the outstanding application ability for applying the computing knowledge, solutions and applications, and computing systems to his or her business tasks in a firm of computing environment. The measurement indices of the computing concepts, the computing knowledge, and the computing application were also quite a high, but the measurement indices of the computing experience were very low.

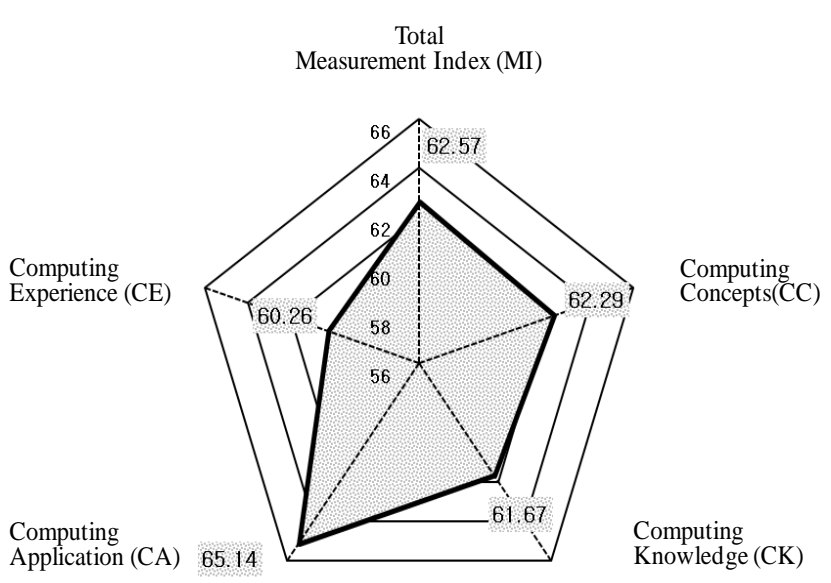

Fig. 4. Measurement Indices of an end-user in BAD.

Therefore, this end-user should make an effort to complete the computing certificate, working experience, and education and training related to the computing departments in order to 
effectively develop his or her total computing competency.

\section{CONCLUSION}

This study presents a framework and items that can efficiently measure the ECC in an enterprise computing environment. It provides the concrete measurement items in terms of an end-user computing competency. The application and utilization of this measure was confirmed by a case study.

The developed scale provides a new direction and groundwork for the development and advance of a measurement instrument since it functions as a measure that can entirely gauge it in respect to the required end-user computing ability in a computing environment.

In future research, we will develop a measurement framework that can examine an ECC considered the characteristics of each business department and position level of individuals in an enterprise of computing environment.

\section{ACKNOWLEDGMENT}

The research was supported by a grant from the Academic Research Program of Korea National University of Transportation in 2013.

\section{REFERENCES}

[1] G. Torkzadeh and J. W. Lee, "Measures of Perceived End-user's Computing Skills," Information \& Management, vol. 40, pp. 607-615, 2003.

[2] R. P. Bostrom, L. Olfman, and M. K. Sein, "The importance of learning style in end-user training," MIS Quarterly, vol. 14, no.1, pp. 101-119, 1990.

[3] P. H. Cheney, R. Mann, and D. L. Amoroso, "Organizational factors affecting the success of end-user computing," Journal of Management Information Systems, vol. 3, no. 1, pp. 65-80, 1986.

[4] J. Rockart and L. Flannery, "The management of end user computing," Communication of the ACM, vol. 26, no. 10, pp. 776-784, 1983.

[5] J. Martin, Application Development without programmers, Prentice-Hall, Eaglewoods, Cal., 1982.

[6] E. R. McLean, "End-user of application developers," MIS Quarterly, vol. 10, no. 4, pp. 37-46, 1979.

[7] W. J. Doll and G. Torkzadeh, "The measurement of end-user computing involvement," Management Science, vol. 35, no. 10, pp. 1151-1171, 1989.

[8] C. Brancheau and V. Brown, "The management of end-user computing: Status and Directions," ACM Computing Surveys, vol. 25, no. 4, pp.437-482, 2002.

[9] R. E. Boyatiz, The Competent Manager: A Model for Effective Performance, N.Y., John Wiley \& Sons, 1982.

[10] R. T. Arthey, and S. M. Orth, "Emerging competency methods for the future", Human Resource Management, vol. 38, no. 3, pp. 215-226, 1999.

[11] D. Rodriguez, R. Patel, A. Bright, D. Gregory, and M. K. Gowing, "Developing Competency Models to Promote Integrated Human Resource Practices," Human Resource Management, vol. 41, no. 3, pp. 309-324, 2002.
[12] R. L. Cardy and T. T. Selvarajan, "Competencies: Alternative frameworks for competitive advantage", Business Horizons, vol. 49, no. 3, pp. 235-245, 2006.

[13] C. Y. Yoon, "Development of a measurement model of personal information competency in information environment," Korea Information Processing Society, vol. 14-D, no. 1, pp. 131-138, 2007.

[14] J. Brownell, "Leading on land and sea: Competencies and context," International Journal of Hospitality Management, vol. 27, no. 2, pp. 137-150, 2008.

[15] J. Peppard and J. Ward, "Beyond strategic information systems: towards an IS capability," Journal of Strategic Information Systems, vol.13, no. 2, pp. 167-194, 2004.

[16] L. M. Spencer and S. M. Spencer, Competence at Work: Models for Superior Performance, John Willy \& Son Inc., 1993.

[17] F. N. Kerlinger, Foundations of Behavioral Research, McGraw-Hill, New York, 1978.

[18] W. J. Doll and G. Torkzadeh, "The measurement of end-user's computing satisfaction,” MIS Quarterly, vol. 12, no. 2, pp. 982-1003, 1988.

[19] E. A. Jamshid and A. F. Farhoomand, "A structural model of end user computing satisfaction and user performance," Information \& Management, vol. 30, pp. 65-73, 1996.

[20] G. Torkzadeh and W. J. Doll, "The development of a tool for measuring the perceived impact of information technology on work, omega," International Journal of Measurement Science, vol. 27, pp. 327-339, 1999.

[21] K. Klenke, "Construct measurement in management information systems: A review and critique of user satisfaction and user involvement instruments," INFOR, vol. 30, no. 4, pp. 325-348, 1992.

[22] G. A. Churchill, "A paradigm for developing better measures of marketing constructs," Journal of Marketing Research, vol. 16, no. 1 , pp. 64-73, 1979.

[23] P. C. Palvia, "A model and instrument for measuring small business user satisfaction with information technology," Information and Management, vol. 31, no. 3, pp. 151-163, 1996.

[24] P. J. Hu, P. Y. K. Chau, O. R. Liu Sheng, and K. Y. Tam, "Examining the technology acceptance model using physician acceptance of telemedicine technology," Journal of Management Information Systems, vol. 16, no. 2, pp. 91-112, 1999.

[25] C. Y. Yoon, "A comprehensive instrument for measuring individual competency of it applications in an enterprise it environment," IEICE Trans. on Information and Systems, vol. E95-D, no. 11, pp. 2651-2657, 2012.

[26] A. M. Aladwani and P. C. Palvia, "Developing and validating an instrument for measuring user web quality," Information and Management, vol. 39, no. 6, pp. 467-476, 2002.

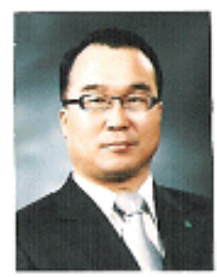

Chui Young Yoon received the Ph.D. degree in Computer Science \& Industrial System Engineering from Yonsei University, Seoul, South Korea in 2003 He worked as a professor at Seoul Cyber University for 2003-2005 and an associate professor at College of Electrical \& Computer Engineering in Chungbuk National University for 2006-2010, and he is also a professor at Department of IT-Applied Convergence in Korea National University of Transportation, Chungju City, Chungbuk, South Korea. He has registered in Marquis Who's Who in the World/Science and Engineering (2009-2012), "Great Minds of the 21st Century" (2010-2012), ABI, and "Outstanding Intellectuals of the 21st Century"(2010-2012), IBC. He has participated as the TPC member and section chair of IEEE IEEM, ICMIT, CSCWD international conferences. His research interests include information system, knowledge-based systems, and measurement of individual competency, human-computer interaction, web-based system and ubiquitous computing technology. 